\title{
A THREE-STAGE MASS SPECTROMETER FOR ISOTOPIC ANALYSIS OF RADIONUCLIDES IN ENVIRONMENTAL SAMPLES
}

J. E. HALVERSON
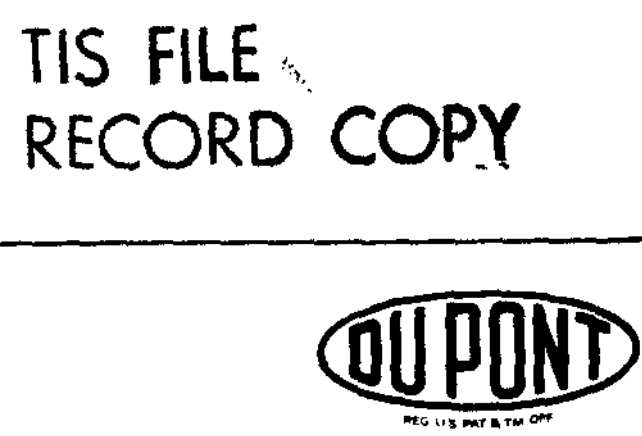

E. I. du Pont de Nemours \& Co. Savannah River Laboratory Aiken, SC 29808 


\section{DISCLAIMER}

This report was prepared by E. I, du Pant de Nemours and Company (Du Pont) for the United States Department of Energy under Contract DE-AC09-76SR00001 and is an account of work performed under that Contract. Neither the United States, the United States Department of Energy nor Du Pont, nor any of their employees, makes any warranty, express or implied, or assumes any legal liability or responsibility for the accuracy, completeness, or usefuiness of any information, apparatus, product, or process disclosed herein, or represents that its use will not infringe privately owned rights. Reference herein to any specific commerical product, process, or service by trade name, mark, manufacturer, or otherwise does not necessarily constitute or imply endorsement, recommendation, or favoring of same by Du Pont or by the United States Government or any agency thereof. The views and opinions of authol's expressed herein do not necessarily state or reflect those of the United States Government or any agency thereof.

Printed in the United States of America

$$
\text { Available from }
$$

Netional Technical Information Service

U. S. Department of Commerce

5285 Port Royal Road

Springtiele, Virginis 22161

Price: Printed Copy $A 02$. Microfiche A01 
DP-1611

Distribution Category: UC-37

\section{A THREE-STAGE MASS SPECTROMETER FOR ISOTOPIC ANALYSIS OF RADIONUCLIDES IN ENVIRONMENTAL SAMPLES}

\section{J. E. HALVERSON}

Approved by

T. V. Crawford, Research Manager

Environmental Sciences Division

Publication Date: September 1981

E. I. du Pont de Nemours \& Co. Savannah River Laboratory Aiken, SC 29808 
A three-stage mass spectrometer was constructed for isotopic analysis of several radioactive as well bs stable elements at environmental levels. The spectrometer is interfaced to a digital computer, which controls the operation of the spectrometer, accumulates data, reduces data, and prints a final result.

The spectrometer has demonstrated the capability of measuring the isotopic composition of plutonium samples as small as 0.005 picogram and has an abundance sensitivity greater than $10^{8}$. 


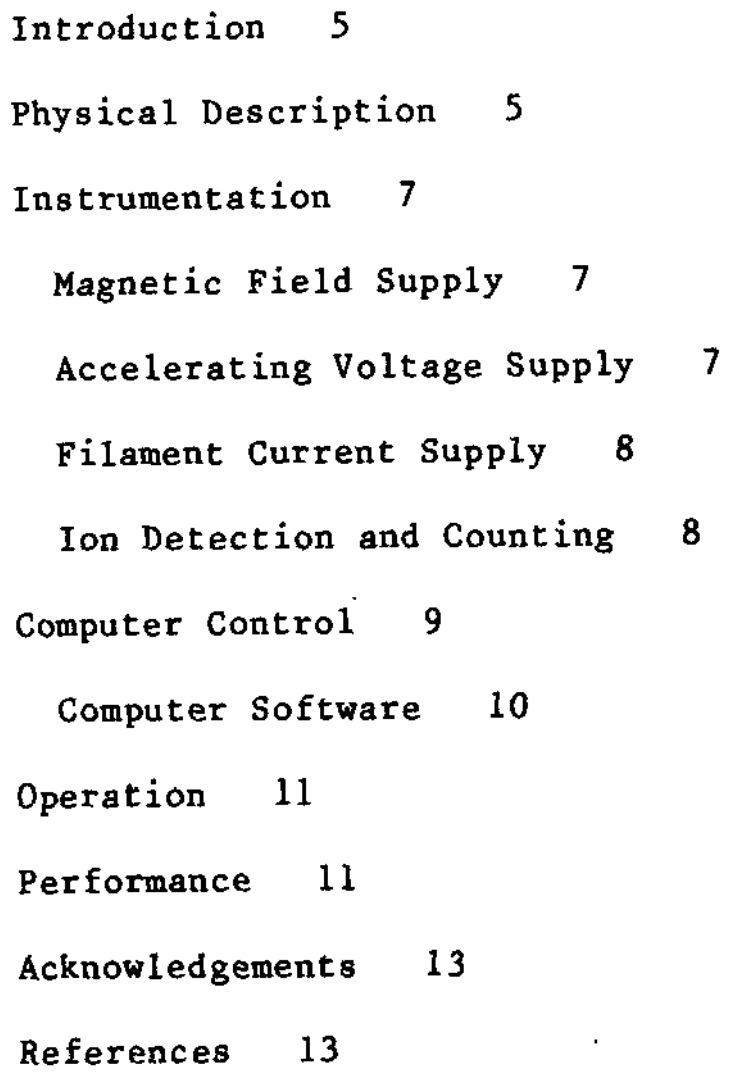




\section{A THREE-STAGE MASS SPECTROMETER FOR ISOTOPIC ANALYSIS OF RADIONUCLIDES IN ENVIRONMENTAL SAMPLES}

\section{INTRODUCTION}

Isotopic signatures of several elements including plutonium, uranium, and technetium help to determine the physical and chemical transport of these elements in the environment. A three-stage mass spectrometer capable of isotopic analyses of these elements and others in environmental samples has been constructed. The spectrometer is similar in design to other spectrometers with demonstrated high abundance and sample sensitivity, 1-3 consisting of $v$-filament surface ionization source and two magnetic analyzers followed by an electrostatic analyzer. The instrument has demonstrated an abundance sensitivity of $1.7 \times 10^{8}$ and is capable of routine isotopic analyses of plutonium samples between 0.005 and 10 picograms.

The spectrometer is interfaced to a PDP $11 / 34$ computer and is highly automated; minimal operator interaction is required. The instrument was automated without sacrificing adaptability or the capability of manual operation.

\section{PHYSICAL DESCRIPTION}

The mass spectrometer ion source is a v-filament surface ionization source developed by Dietz. 4 This design was chosen because of its high ionization efficiency and transmission. The filaments are loaded into the vacuum system five at a time on a holder resembling a ferris wheel. This permits analysis of 15 samples per eight-hour shift.

The arrangement of the spectrometer is shown in Figures 1 and 2. It consists of two $90^{\circ}$ sector, 30.48-cm-radius, normal entry and exit magnetic analyzers in a $C$ configuration followed by a 30.48-cm-radius, $90^{\circ}$ electrostatic analyzer. This configuration results in zero mass dispersion at the point of focus of the ions emerging from the second magnet. The magnets are mounted on tracks, which permit translational motion for tuning along a line bisecting the $90^{\circ}$ sector angle. The magnets have a $2.03-\mathrm{cm}$ gap and can produce a field of 10 kilogauss.

The electrostatic analyzer consists of two cylindrical plates $3.18 \mathrm{~cm}$ high with a separation of $1.27 \mathrm{~cm}$. The plates have tapered Rose shims for field uniformity ${ }^{5}$ and are terminated with 


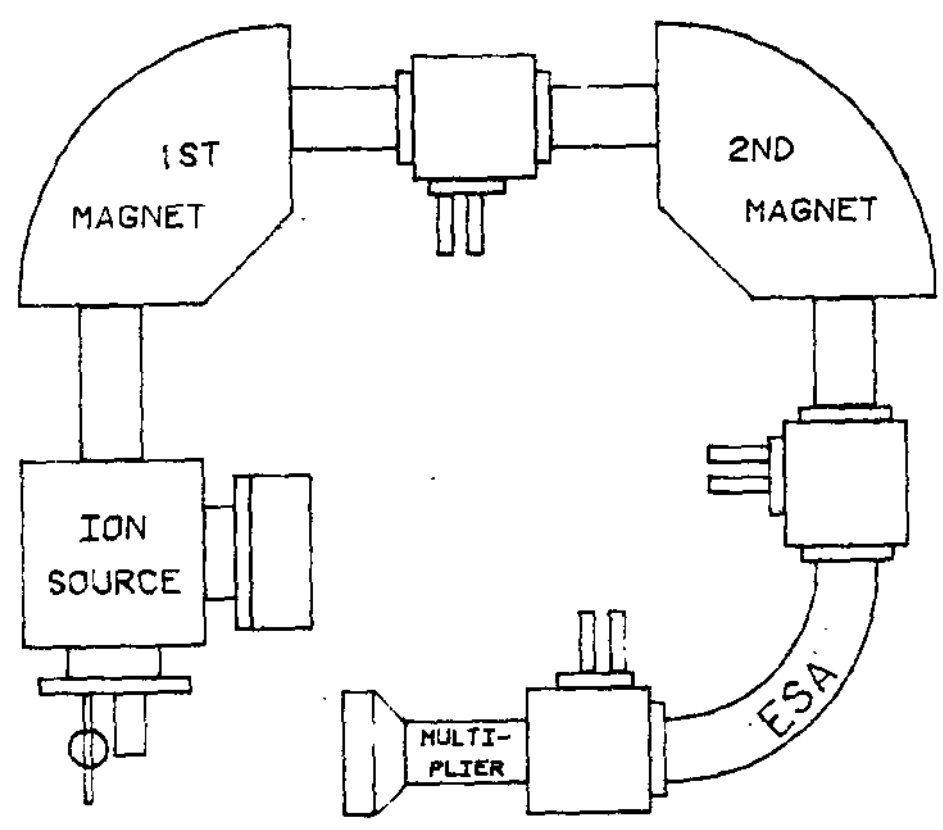

FIGURE 1. Three-Stage Mass Spectrometer

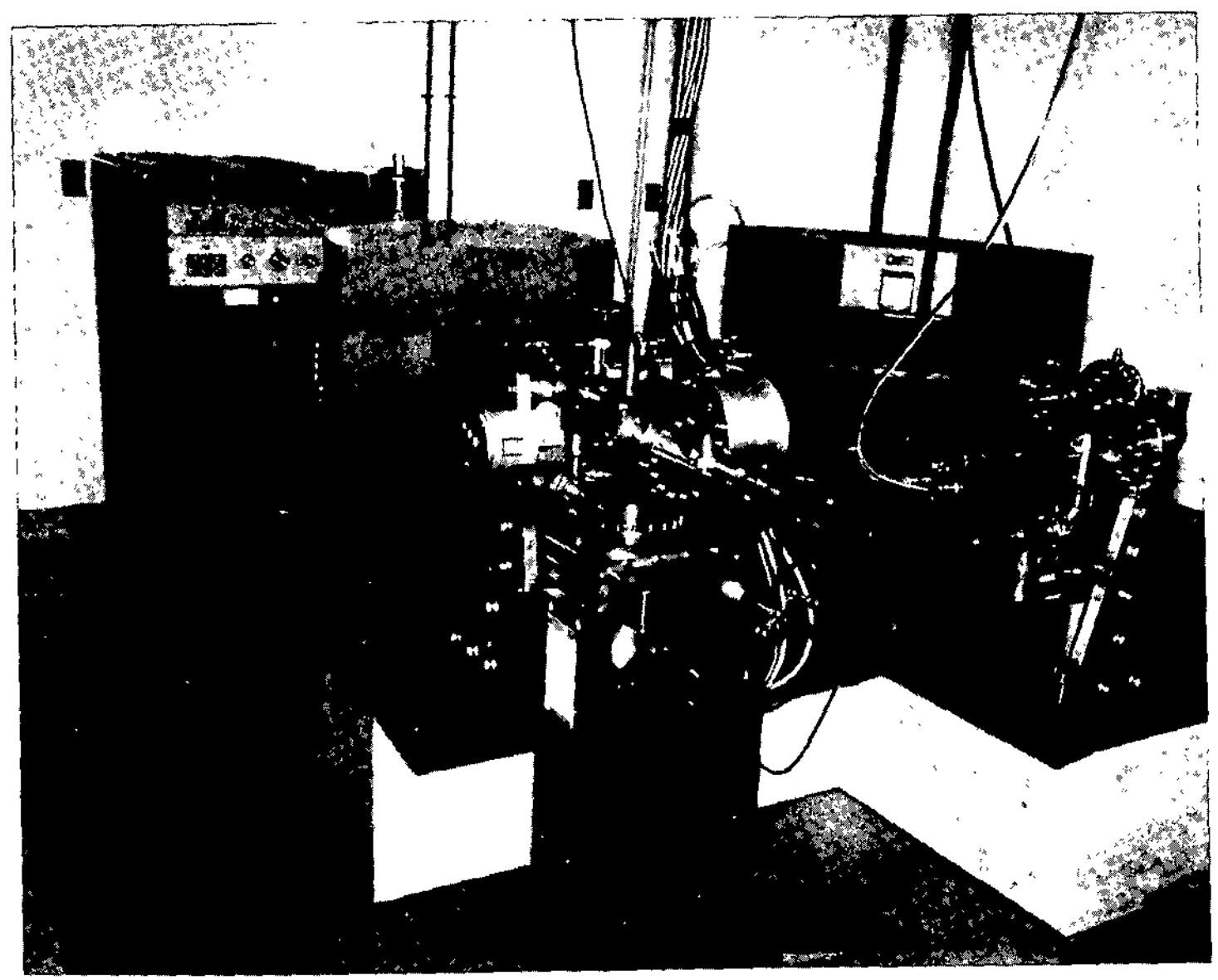

FIGURE 2. Spectrometer 
grounded end plates. The orientation of the analyzer plates about their entry and exit points is adjustable by means of a linearmotion vacuum feedthrough positioned at the apex of the analyzer plates. This permits alignment of this stage while the spectrometer is in operation.

The entire vacuum system is fabricated from stainless steel. All flanges are copper gasketed, with the exception of the multiplier housing and the source access port, which are both sealed with Viton (Trademark of Du Pont) o-rings. The vacuum pumping system is entirely oil free. Rough pumping is achieved using a carbon vane pump and a two-stage sorption pump. Source vacuum is maintained below $10^{-7}$ torr during operation by a $220-\mathrm{L} / \mathrm{sec}$ triode ion pump and a liquid-nitrogen cold "finger." The flighttube pressure is kept below $5 \times 10^{-8}$ torr at all times by four $20-\mathrm{L} / \mathrm{sec}$ triode ion pumps and a source-isolation valve, which permits samples to be introduced into the source without breaking the flight-tube vacuum.

\section{INSTRUMENTATION}

The mass spectrometer's support instrumentation is shown schematically in Figure 3.

\section{Magnetic Field Supply}

A field-regulated, 80-volt, 50-ampere power supply provides current to the magnets. The magnitude of the magnetic field is monitored by a hall probe placed in the field gap of the first magnet. A 15-volt, $1-\mathrm{kHz}$ signal is supplied to the Hall probe, and this signal is compared to the Hall effect current. The difference between the two signals is used as the regulating feedback signal for the magnet current supply. The two magnets are wired in series, and the second magnet is wound with extra coils so that a trim pot placed in parallel with the coils can be adjusted in such a manner as to bleed off enough current from the second magnet to match its field with the first magnet.

\section{Accelerating Voltage Supply}

A Nuclide HV 122 programmable $20-\mathrm{kV}$ power supply is used as the source accelerating voltage supply to permit sweeping and peak stepping. Although voltage switching can cause more bias than magnetic switching, this mode of peak stepping is preferable for environmental samples because it is inherently faster. This results in better time utilization for analyzing environmental samples, which are typically very small. Also, because the samples are so small, 
the error introduced by counting statistics often masks any bias caused by voltage switching. Similarly, the small voltage steps required for isotopic analyses of heavy elements also tend to limit the effects of source voltage related biases. Output from the high-voltage power supply is fed into two variable-resistor voltage dividers, the source divider and the electrostatic-analyzer source divider. The source divider is a constant-load device, enabling tuning without changing the load on the HV power supply. This eliminates any possibility that inadequate load regulation of the power supply could cause the accelerating potential to drift during source tuning.

\section{Filament-Current Supply}

A series of three transformers are used to supply the filament current. The first transformer is a constant-voltage $110-\mathrm{V}$ transformex. This transformer is the only regulation required to maintain a stable filament temperature if proper care is taken to maintain clean filament contacts on the ferris wheel. Filament temperature is controlled by a variable transformer supplied by the constant-voltage transformer. The output of the variable transformer is fed to a custom-made, oil-filled transformer capable of isolating the $20-\mathrm{kV}$ source voltage. This transformer is 110-V input, 5-V, 20-A center-tapped output unit. The center tap is connected to the source voltage to minimize the potential difference between the ends of the filament and the source shield plate. To ensure reproducible results, an infrared noncontact thermometer is used to monitor the filament temperature. The output of this unit is in the control console directly above the filament-current control transformer.

\section{Ion Detection and Counting}

The ion-beam intensity is measured by a pulse-counting multiplier originally designed by Dietz. 6 The multiplier presently in use was built at the Savannah River Laboratory (SRL). It has virtually $100 \%$ detection efficiency with a very low background (less than 4 counts per hour) and a gain of $10^{8}$.

Output from the multiplier is amplified by a custom built discriminator-preamplifier mounted on the multiplier housing. The output from this unit is $-3.0-\mathrm{V}, 15-$ nanosecond pulses, which are fed to a 125-megahertz Fluke universal counter-timer. The dead time for the entire counting system has been measured to be less than 20 nanoseconds. 


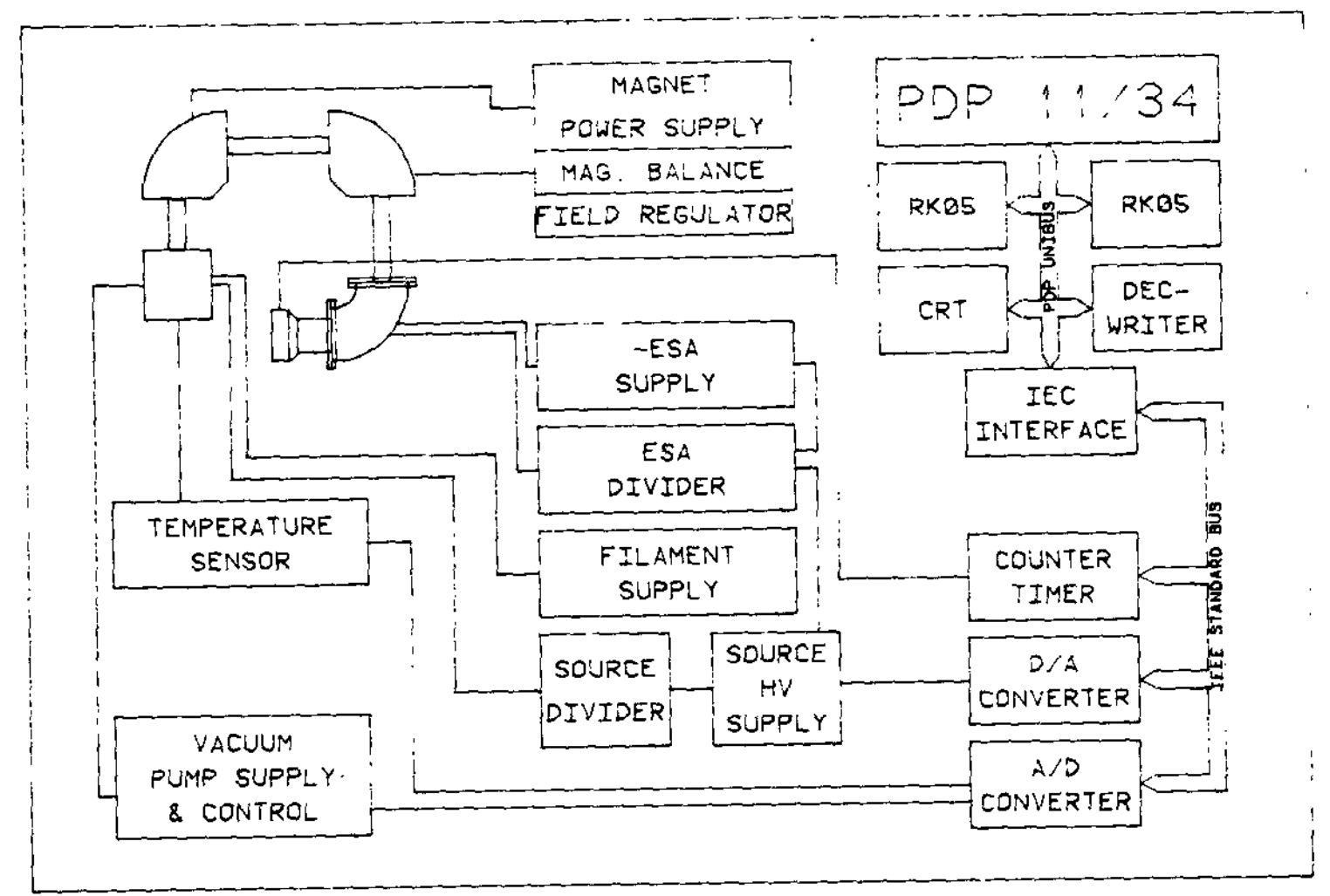

FIGURE 3. Mass-Spectrometer Electronics and Computer Controls

\section{COMPOTER CONTROL}

The spectrometer is highly automated; both the construction of the instrument and the software development were designed to permit further automation and to maintain flexibility.

A digital computing system consisting of a PDP $11 / 34$ processor, $124 \mathrm{~K}$ words of memory, two 2.4-megabyte disks, a console printer, and a graphics terminal is interfaced to the spectrometer by an IEEE 488 standard data bus. The IEEE data bus permits control of up to sixteen devices. At present, it is interfaced to the Fluke counter timer, a Nuclide 16-bit digital-to-analog converter (DAC), and a data acquisition instrument (DAI) designed and built at SRL. 7 
Output of the DAC is used as the programning potential for the source accelerating voltage power supply. Circuitry was added to the DAC to make it compatible with the IEEE standard handshake process. Data are sent to the DAC in binary form, byte serially, least significant byte first. This method of data transfer avoids the problems and time delays associated with encoding and decoding $B C D$ or ASCII coded data, the more typical methods of data transfer on the IEEE bus.

The data acquisition instrument is a 16-channel, 12-bit analog-to-digital converter. Each input channel has an independent amplifier to permit measurement of a wide variety of voltage ranges. At present, the device is used to monitor the vacuum pumps and filament temperature. The computer warns the operator at the control terminal when analog signals measured by the DAI are abnormal. The spectrometer could be programmed to respond to any abnormal situation automatically by interfacing the appropriate valves and switches to the computer via the IEEE data bus.

The Fluke counter timer is operated in two modes. During source tuning, the counter is in a free-running mode and displays the count frequency measured in the previous second. While an analysis is in progress, the counter timer is triggered by a command from the computer after the appropriate source voltage for a particular isotope has been set and enough time for the supply to reach the correct level has passed. The counter timer then counts for a preset time and issues a service request on the IEEE data bus upon completion of the count. This arrangement frees the computer central processing unit for data reduction or other low priority tasks during data acquisition and utilizes the very accurate timing circuitry of the frequency counter for measuring count frequencies.

\section{Computer Software}

Versatility, speed, and ease of operation were the primary factors considered when writing the mass spectrometer control and data acquisition programs. Thus, individual tasks and subroutines were written to handle each particular function, and the RSX11-M system executive is used to manage both computer and instrument resources most efficiently. In addition, commonly used information, such as often used analysis procedures, is stored in files on the RK05 disk. To permit unusual analyses, these files can be edited using the system editor, or new routines can be devised interactively from the control terminal at analys is time. 
Analysis of a typical sample consists of two steps for the operator, source tuning and analysis initialization. After the analysis is initialized, spectrometer operation is entirely automatic.

Source tuning consists of aligning the proper filament with the ion-source plates, slowly increasing filament temperature, and then adjusting the source-plate voltage for maximum ion-beam strength,

Initialization of an analysis involves entering a number of parameters into the computer from the control console. These parameters specify operation modes and data handling methods. One of three standard analyses can be selected by indicating the proper file name. The three files each contain a list of masses and count times for each mass. Also, the options to sweep through any. mass range and to generate a specialized list of masses and times are available.

Other options include plotting data, storing data, simultaneous data reduction; and the capability to make a fast scan of the isotopes to determine optimum times for counting a mass peak to minimize the variances of the estimated isotopic composition. Optimizing counting times was discussed by Jaech, 8,9 whose methods were incorporated into a routine that calculates new counting times for each mass peak based on the results of a preliminary fast scan.

\section{PERFORMANCE}

The abundance sensitivity of the three-stage mass spectrometer was measured using an NBS standard uranium sample (U005, $235 \mathrm{U} / 238 \mathrm{U}=0.004919)$. Table 1 summarizes a typical abundance sensitivity test in which nearly 200,000 counts were accumulated in $14 \mathrm{sec}$ at the mass 235 position; on $1 \mathrm{y} 12$ counts were accumulated in $700 \mathrm{sec}$ at the mass 237 position. Because the ratio of $238_{U}$ to $235_{U}$ for this sample was measured in analyses immediately preceding and following the sensitivity test to be approximately 200 to 1 , the contribution of the tail of the major peak at mass 238 to the neighboring mass peak one unit away is calculated to be less than six parts per billion.

The spectrometer is being used routinely to measure the isotopic composition of plutonium samples between 0.005 and $10 \mathrm{pg}$. The overall efficiency, including the chemical purification, the spectrometer transmission efficiency, and the ionization efficiency, is typically $0.5 \%$ for these samples. 


\section{TABLE 1}

\section{Abundance Sensitivity*}

Mass 235 , counts $/ 2 \mathrm{sec}$ Mass 237 , counts/100 sec

$\begin{array}{lll} & 17153 & 2 \\ & 23032 & 3 \\ & 25787 & 0 \\ 29095 & 2 \\ & 32398 & 3 \\ & 35058 & 2 \\ \text { Total } & 36647 & 0 \\ \text { Rate } & 199280 & 12 \\ & 14200 \mathrm{cps} & 0.17 \mathrm{cps}\end{array}$

*Sensitivity $=R_{238} / R_{237}=R_{238} / R_{235} \times R_{238} / R_{237}=$ $200 \times 8.35 \times 10^{5}=1.67 \times 10^{8}$. 


\section{ACKNOWLEDGMENTS}

I am greatly indebted to L. A. Dietz and C. F. Pachucki of the Knolls Atomic Power Laboratory and C. R. Lagergren of Pacific Northwest Laboratory for their invaluable advice and encouragement during the design, construction, and testing of the spectrometer.

I would also like to express my gratitude to $T$. R. Herold of the Savannah River Laboratory for his excellent work in the fabrication of the electron multipliers, the discriminator preamplifier, and much of the source electronic equipment.

\section{REFERENCES}

1. F. A. White, F. M. Rourke, and C. J. Sheffield. Appl. Spectros. 12, 46 (1958).

2. L. A. Dietz, C. F. Pachucki, J. C. Sheffield, A. B. Hance, and L. R. Hanrahan. Anal. Chea. 32, 1276 (1960).

3. C. R. Lagergren and J. J. Stoffels. Int. Mass Spectrom. Ion Phys. 3, 429 (1970).

4. L. A, Dietz. Rev. Sci. Instr. 30, 235 (1959).

5. L. A. Dietz, Rev. Sci. Instr. 32, 849, (1961).

6. L. A. Dietz. Rev. Sci. Instr. 36, 1763 (1965).

7. J. S. Byrd. "Analog Data Acquisition with Commodore Pet and the IEEE 488 Bus." (To be published in COMPUTE.)

8. J. L. Jaech. Anal. Cher, 36, 1164 (1964).

9. J. L. Jaech. Anal. Chea. 36, 2196 (1965). 